\title{
Advancing Service Integration in Opioid Treatment Progams for the Care and Treatment of Hepatitis C Infection
}

\author{
Thomas F. Kresina, Robert Lubran, H. Westley Clark, Elinore F. McCance-Katz
}

Substance Abuse and Mental Health Services Administration, Rockville, USA.

Email: tkresina@SAMHSA.gov

Received December $13^{\text {th }}, 2013$; revised January $5^{\text {th }}, 2014$; accepted January $20^{\text {th }}, 2014$

Copyright (c) 2014 Thomas F. Kresina et al. This is an open access article distributed under the Creative Commons Attribution License, which permits unrestricted use, distribution, and reproduction in any medium, provided the original work is properly cited. In accordance of the Creative Commons Attribution License all Copyrights (C) 2014 are reserved for SCIRP and the owner of the intellectual property Thomas F. Kresina et al. All Copyright (C) 2014 are guarded by law and by SCIRP as a guardian.

\section{ABSTRACT}

It is estimated that approximately 200 million people globally are infected with the hepatitis $\mathrm{C}$ virus and that roughly half of these people live in Asia. Without treatment, it is estimated that roughly twenty percent of those infected with hepatitis $C$ virus progress to chronic liver disease, then subsequently, end-stage liver disease. Thus, access to hepatitis $C$ testing and subsequent care and treatment of chronic hepatitis $C$ infection are essential to address the global burden of disease. In the United States, the Center for Disease Control and Prevention estimates that $60 \%$ of new cases of hepatitis infection are due to injection drug use. Opioid Treatment Programs (OTP's) dispense methadone and buprenorphine under specific federal regulations to injection drug users diagnosed with opioid dependence. OTPs are developing comprehensive care and treatment model programs that integrate general medical and infectious disease-related medical care with substance abuse and mental health services. Integrating hepatitis care services and treatment in the substance abuse treatment settings foster access to care for patients with hepatitis $C$ infection, many who otherwise would not receive needed care and treatment. This may serve as a national model for highly cost-efficient healthcare that has a measurable outcome of improved public health with reduced hepatitis $\mathrm{C}$ prevalence.

\section{KEYWORDS}

Opioid Treatment Programs; Hepatitis C Treatment; Methadone; Buprenorphine

\section{OTP's, Opioid Dependence and Hepatitis C Infection}

Opioid dependence, resulting from opioid injection drug use or opioid prescription drug abuse, is a significant public health problem [1]. Research studies have clearly shown that addiction to drugs of abuse is a brain disease, and if left untreated, progresses to chronic debilitating outcomes with associated medical and psychiatric comorbidities [2]. Therefore, opioid dependent individuals may manifest complex medical and social problems that require both substantial medical care and the medical management of substance abuse. Infectious diseases associated with injection drug use include viral hepatitis infections, particularly hepatitis $\mathrm{C}$ virus infection. The Centers for Disease Control and Prevention (CDC) has estimated that $60 \%$ of all new cases of hepatitis $C$ infection are related to injection drug use [3].

In the United States, OTP's dispense methadone to approximately 225,000 individuals nationwide [4] from over 1200 individual Substance Abuse and Mental Health Services Administration certified treatment programs. These programs can also provide buprenorphine as authorized under 21 U.S.C. Section 823 (g) and approximately 1300 patients receive buprenorphine for the treatment of opioid dependence through OTP's. However, it has been estimated that there are at least 800,000 untreated injection-heroin users in the United States with an even larger number of opioid dependent prescription drug users [5]. Left untreated, opioid abuse and dependence result in a reduced quality of life in both physical 
and mental functioning compared to the general population [6,7]. The multiple medical and social comorbidities associated with substance abuse and addiction also contribute to the lower quality of life experienced and documented by opiate users $[7,8]$. Life priorities of injection drug users include, a concern about and treatment of infectious diseases, such as hepatitis $\mathrm{C}$ infection, as well as, social and fiscal issues such as housing, money, and protection from violence [9]. Studies have shown that individuals receiving methadone treatment are at a reduced risk of death, less involved in crime, and have an enhanced quality of life, with positive cognitive, emotional, and social functioning [10-13].

For individuals with opioid dependence, OTP's are required by federal regulation to establish an individualized substance abuse treatment plan as part of long term methadone or buprenorphine treatment. Utilizing case management, a comprehensive substance abuse treatment plan can be developed that comprises behavioral, social rehabilitative components, and biological (pharmacological) treatments, (Table 1). An effective treatment strategy for drug abuse and dependence is to match a comprehensive treatment plan to the individual's particular substance abuse problems and needs. Desired treatment outcomes are: 1) reduce dependence on drugs of abuse, 2 ) reduce morbidity and mortality of infectious diseases associated with drugs of abuse, particularly hepatitis C infection, and 3) maximize the patients' abilities to access services and achieve social integration. Treatment outcome measures to be followed include quality of care, client perception of care, cost effectiveness of the substance abuse treatment plan and use of evidence-based practices.

A substantial body of knowledge exists documenting the effectiveness of pharmacological therapies, as part of a comprehensive substance abuse treatment plan, in reducing heroin use and providing an opportunity for improvement in health and social functions for individuals addicted to opioids [14-16]. Two Treatment Improvement Protocols (TIPs) from SAMHSA provide the best practices guidelines for the use of either methadone or buprenorphine as part of a comprehensive treatment plan for opioid addiction $[17,18]$. Positive treatment outcomes are based on greater retention time in treatment and patient satisfaction with treatment services. Maximum retention time in methadone treatment is associated with comprehensive treatment, provision of frequent and quality health services, as well as, appropriate methadone dosing.

\section{Integrating Hepatitis Infection Services into Comprehensive Substance Abuse Treatment Plans}

In addition to pharmacotherapies for opioid dependence,
Table 1. Pharmacotherapy and behavioral therapy comprising a comprehensive substance abuse treatment plan.

Pharmacotherapy
1) Opioid Dependence
Methadone-federally regulated through Opioid Treatment Programs,
opioid receptor agonist for substitution therapy
Buprenorphine-office based opioid treatment or Opioid Treatment
Programs, federally regulated, partial opioid receptor agonist for
substitution therapy
Naltrexone (extended release naltrexone)—office-based and
substance use treatment programs when opioid abstinence is possible
and without significant relapse risk, opioid receptor antagonist for
relapse prevention
2) Alcohol Dependence
Naltrexone (extended release naltrexone)—an “anti-craving” agent,
opioid receptor antagonist, reduced reward effect, with daily use,
new forms are long acting
Acamprosate—an "anti-craving” agent that normalizes glutamater-
gic neurotransmission, slow acting, attenuates relapse
Disulfiram—a “vicarious” aversive medication supporting complete
abstinence to alcohol that blocks complete oxidation of alcohol with
accumulation of acetaldehyde and resultant unpleasant “allergic"
physical symptoms when alcohol is absorbed (e.g., flushing,
headache, and vomiting).

3) Nicotine Dependence

a) Nicotine replacement therapy, many over the counter, such as patches, gum and inhalers used to replace the daily physical requirement for nicotine and may be used for nicotine withdrawal or maintenance.

b) Buproprion —an antidepressant also found to be an "anti-craving” agent that reduces the psychological craving for tobacco.

c) Varenicline- - a partial nicotine receptor agonist FDA approved for treatment of nicotine dependence and relapse prevention.

Behavioral Therapy

1) Brief interventions-for 1 to 3 visits (low intensity), for early drug use and substance abuse, in many different outpatient settings

2) Motivational enhancement interviewing and therapy 3) "12-step" facilitation

4) "stage of change" model interventions

5) Long term multi-modal and multi-dimensional comprehensive therapies and interventions - to restructure belief and cognitive systems, enhance coping strategies, change friendships and environment, and change behavior

1) Individual interpersonal therapy such as cognitive behavioral therapy and insight-oriented psychotherapy

2) Group therapy — such as family or faith based, Therapeutic Communities

3) “12-step” programs and "clean and sober” recovery living environments where peer groups interested in sobriety mutually help one another stay sober

a comprehensive substance abuse treatment plan for injection drug users needs to address viral hepatitis infection. Thus, for patients receiving methadone at an OTP, testing and vaccination to prevent hepatitis A and hepatitis B virus infections are important health care measures that are recommended by the CDC. The Substance Abuse and Mental Health Services Administration has developed a pilot program to test the efficacy of delivering vaccination against hepatitis $A$ and hepatitis $B$ infections in OTPs [19]. With the high prevalence of hepatitis C 
infection and reasonable likelihood of eventual hepatitis $\mathrm{B}$ and hepatitis A infection, a preventive strategy can be to patients receiving methadone treatment to reduce the risk of potential future infection. This can be a potentially successful prevention service since patient care is carefully documented to meet daily reporting requirements with over half the nation's opioid treatment programs using a computerized record system that identifies the patient and tracks medication delivery.

In a survey of hepatitis testing services provided by OTP's nationwide [20], a graduated level of services were reported as provided with $61.9 \%$ of OTP's providing HBV testing, $64.4 \%$ providing HCV testing, $74 \%$ providing HIV testing, and $88.9 \%$ providing HIV education. Recent studies of hepatitis testing in OTPs have shown over $75 \%$ of programs nationally report capacity to provide hepatitis C testing [21] but that for-profit opioid treatment programs are less likely to make hepatitis $\mathrm{C}$ testing services available. One such study reported on a representative sample of programs and found as few as $34 \%$ of programs offering on-site testing for hepatitis C infection [22]. It is important for OTPs to increase their surveillance for hepatitis infection, not decrease it. Patient education about hepatitis and liver disease, as well as prevention, of hepatitis infection and enrollment in primary medical care are important in the medical management of acute and chronic stages of viral infections in the liver [23]. Counseling of young injection drug users, regarding prevention of hepatitis infection, is critical since roughly half of injectors, under the age of 23, may be free of viral hepatitis infections [24]. However, young injection drug users are frequently not vaccinated or educated to prevent viral hepatitis infection [25]. Counseling individuals, who have hepatitis infection, about a healthy lifestyle promotes treatment readiness for those individuals with progressive liver disease [26]. Providing integrated primary care and pharmacologic treatment for opioid dependence for the substance abuser can facilitate both recovery from opioid addiction and viral hepatitis infections [27]. Integration of services has also been shown to increase the quality of treatment and prevention services as well as health-related quality of life for people who inject drugs [28].

For individuals with hepatitis infection, there are current clinical practice guidelines that recommend care and treatment for patients, who benefit by treatment and virus eradication. However, barriers to hepatitis care and treatment exist for patients receiving methadone at OTP's $[23,29,30]$. These include a generalized stigma and prejudice associated with substance-dependent persons, disenfranchisement of drug users from the medical community, the complex medical management issues of drug abusers, a lack of current treatment knowledge for patients who are injection drug users by providers, as well as, a lack of infrastructure to deliver effective care to injection drug users [31,32]. The consequence has been delayed or withheld treatment for chronic liver disease due to hepatitis $C$ infection in current or former substance-dependent persons, as well as for those in recovery from addiction receiving pharmacologic therapies. Individuals not receiving care and/or treatment for hepatitis infection, as well as those not responsive to hepatitis treatment will progress to end-stage liver disease, or decompensated cirrhosis, leaving orthotopic liver transplantation as the only life-saving alternative. Indeed, hepatitis C-related cirrhosis has been the leading etiology of orthotopic liver transplantation [33].

\section{Addressing Patient Needs with Comprehensive Services for Hepatitis Infection}

Individuals seeking therapy, specifically methadone or buprenorphine treatment for opioid dependence may be HCV infected, particularly if they approach drug treatment after years of opioid use [34,35]. Prevalence estimates of hepatitis $\mathrm{C}$ infection in former and current injection drug users, derived from surveys of patients in methadone treatment programs, range from $72 \%$ to greater than $90 \%[34,36,37]$. Yet, routine testing for hepatitis C infection in this population is not common [37]. Routine testing for hepatitis $\mathrm{C}$ infection of individuals who have ever injected illegal drugs has been recommended by the CDC and is part of a national strategy and action plan for the prevention, care and treatment of viral hepatitis infection [34,38]. Further, the US Preventive Services Task Force has now recommended that all Americans born between 1945 and 1965 receive a hepatitis $\mathrm{C}$ test and continued periodic hepatitis $\mathrm{C}$ testing for those determined to be at risk including current or former injection drug users [39]. A significant cohort of patients, now receiving methadone or buprenorphine treatment, need care for chronic hepatitis $C$ infection and eventually may need hepatitis $C$ treatment and/or liver transplantation for survival. Medical care, in combination with education and pharmacological therapies, is important for the medical management of the acute and chronic stages of viral hepatitis infections. Counseling individuals with hepatitis infection about a healthy lifestyle promotes treatment readiness for those individuals with progressive liver disease [26]. Peer driven counseling and testing for hepatitis infection has been shown to change risky behavior of injection drug users associated with the transmission of HCV [40]. Studies have shown the need for staff training and education in the delivery of counseling and testing for hepatitis C infection in OTPs [41].

Comprehensive services for hepatitis infection include prevention as well as hepatitis care and treatment. Elements of hepatitis care for people who use drugs include screening for at-risk behavior; hepatitis testing; preven- 
tion counseling and education; vaccination against hepatitis A and hepatitis B infections; and evaluation for liver disease and comorbidities, including the need for substance abuse services, psychiatric care, and social support. A growing number of studies [42-48] have found that hepatitis treatment regimens are safe and effective for patients in care and receiving methadone treatment, hepatitis pharmacotherapy is not altered by methadone, patients that discontinue hepatitis $C$ therapy while receiving methadone usually do so early in the time course of hepatitis $\mathrm{C}$ treatment, and that stable housing is associated with the initiation of hepatitis treatment. Thus, patients receiving methadone treatment should not be withdrawn from methadone prior to hepatitis C treatment, since continued methadone maintenance can be helpful in enhancing quality of life through stabilization during hepatitis $\mathrm{C}$ treatment. Buprenorphine/naloxone treatment of opioid dependence in the context of treatment for hepatitis $\mathrm{C}$ has not been formally studied, but concerns about the relationship between buprenorphine and hepatotoxicity have been studied and the risk determined to be inconsequential when used therapeutically [49]. The American Association for the Study of Liver Disease (AASLD) Clinical Practice Guidelines recommend that hepatitis $\mathrm{C}$ treatment not be withheld from individuals attending and seeking treatment for $\mathrm{HCV}$ infection in OTPs [50].

\subsection{Early Screening, Testing and Treatment of Acute Hepatitis C Virus Infection}

The optimal methods for detecting hepatitis $\mathrm{C}$ infection are to screen for a history of at-risk behaviors and to test individuals who have an identified risk behavior or factor for hepatitis C virus exposure [51]. In the United States, injection drug use is the predominant mode of hepatitis $C$ virus transmission and anyone with a history of injecting drugs should be tested for hepatitis C virus infection [34]. Health care providers can screen individuals for risk factors, offering testing to those at increased risk for hepatitis $\mathrm{C}$ virus infection, as well as, providing individuals with hepatitis $\mathrm{C}$ counseling, medical evaluation, care, and treatment if needed [52]. Testing for hepatitis $C$ virus infection followed by interferon-based treatment is effective in acute hepatitis $C$ virus infection. Acute hepatitis $C$ virus infection is commonly defined as the first 6 months after exposure to the hepatitis $C$ virus [53]. The diagnosis of acute hepatitis $\mathrm{C}$ virus infection can be difficult in at-risk patients because the acute inflammatory stage of the disease is often asymptomatic and often (25\% - 50\%) patients can undergo spontaneous viral clearance in acute infection [54]. A recent cohort study of treatment in acute hepatitis $\mathrm{C}$ virus infection noted that $52 \%$ of patients spontaneously resolved the virus infection [55].

Nevertheless, the case definition of acute hepatitis C virus infection can be defined using the individual criteria of hepatitis $\mathrm{C}$ antibody conversion, alanine aminotransferase elevation and hepatitis C RNA detection [56]. For those individuals who do not spontaneously resolve their infection, studies have shown interferon-based treatment to be highly effective with sustained viral response (SVR) to treatment ranging from 95\% - 100\% $[55,57,58]$. Thus, treatment of acute hepatitis $\mathrm{C}$ virus infection has been proposed to prevent chronic disease and complications, such as cirrhosis, and is a cost-effective treatment [59]. In the setting of methadone treatment for injection drug use-related opioid dependence, the testing for hepatitis $\mathrm{C}$ virus infection status, use of case definition criteria to establish acute hepatitis $C$ virus infection following by treatment of non-resolving infection is an important public health imperative. The diagnosis and early treatment of hepatitis $\mathrm{C}$ virus infection, utilizing shorter and simpler interferon-based regimens, represent an attractive option for those receiving methadone treatment for injection opioid dependence [60,61].

\subsection{Treatment of Chronic Hepatitis C Infection and Methadone or Buprenorphine Treatment for Opioid Use Disorders}

Treatment of chronic hepatitis $\mathrm{C}$ virus infection with interferon-based treatments has not been as effective as compared to that for acute infection, particularly with genotype I. However, the recent FDA approval of two new oral medications, bocepravir and telapravir termed direct-acting antiviral medications, have been shown to enhance treatment responses of patients with genotype I infection, as well as, those who have previously failed interferon-based treatment [62]. Both methadone and buprenorphine have been shown not to have significant drug interactions with these hepatitis $C$ medications and so can be co-administered [63], although the presence of adverse events should continue to be monitored clinically since experience with these combinations in practice is quite limited to date. The approach to treatment of hepatitis C may soon change to the use of oral medications rather than a combination of interferon, an injected therapeutic and oral medications. Sofosbuvir is the first oral medication approved as a single, once-daily medication treatment for hepatitis C [64] and it is expected that other oral medications will also be approved in the coming years [65]. Oral regimens may be more acceptable to patients and may have fewer adverse side effects than does interferon. In addition, once-daily medications can be administered with methadone or buprenorphine therapy at OTPs if clinically indicated. Directly observed therapy can help with adherence and contribute to improved clinical outcomes for opioid dependence and for hepatitis $\mathrm{C}$.

Mathematical modeling of the scale-up of these new 
medications for the treatment of chronic hepatitis $C$ virus infection in injection drug users indicates that therapy with direct acting antivirals lasting only 12 weeks would achieve a SVR in over $90 \%$ of people who inject drugs [66]. Thus, utilization of the newly approved medications could revolutionize the treatment outcomes for people who inject drugs, as well as for patients receiving methadone treatment. This is partly because clinical investigations of hepatitis $C$ treatments have generally not included patients receiving methadone treatment. Methadone administration has been considered a potentially confounding factor for positive hepatitis $\mathrm{C}$ treatment outcomes and the OTP population has been viewed as atypical [67].

However, studies have shown that patients receiving methadone maintenance treatment are good candidates for treatment, that hepatitis $C$ treatment outcomes from interferon-based treatment regimens for patients receiving methadone treatment can be equivalent to those reported in studies of patient populations excluding patients receiving methadone treatment and that OTPs can deliver interferon-based treatment [37,68-70].

An important area of continuing investigation is how best to provide treatment for chronic hepatitis $\mathrm{C}$ virus infection in a setting of substance abuse treatment, in particular for patients receiving methadone treatment in OTP settings. Studies have integrated hepatitis $C$ virus infection treatment using interferon based treatment and directly observed therapy into an OTP [71,72]. Others have utilized concurrent group treatment [73] and hepatitis care coordination [74] to address barriers to hepatitis $\mathrm{C}$ care and treatment. What is clear is that the provision of both methadone maintenance treatment and treatment for hepatitis $C$ virus infection is important and such public health treatment approaches can reduce hepatitis virus infection and transmission globally in people who use drugs [75,76]. Thus, frameworks can be developed, as well as, national action plans to enhance the global efforts to provide hepatitis prevention, care and treatment to those in need [38,77].

\section{REFERENCES}

[1] L. Degenhart, H. A. Whiteford, A. J. Ferrari, A. J. Baxter, F. J. Charlson and W. D. Hall, "Global Burden of Disease Attributable to Illicit Drug Use and Dependence: Findings From the Global Burden of Disease Study 2010,” Lancet, Vol. 382, No. 9904, 2013, pp. 1564-1574. http://dx.doi.org/10.1016/S0140-6736(13)61530-5

[2] M. J. Kreek, O. Levran, B. Reed, S. D. Schlussman, Y Zhou and E. R. Butelman. "Opiate Addiction and Cocaine Addiction: Underlying Molecular Neurobiology and Genetics,” Journal of Clinical Investigation, Vol. 122, No. 10, 2012, pp. 3387-3393.

http://dx.doi.org/10.1172/JCI60390
[3] CDC (Centers for Disease Control and Prevention), "Hepatitis Surveillance Report No. 59,” United States Department of Health and Human Services. Centers for Disease Control and Prevention, Atlanta. 2004. www.cdc.gov/hepatitis

[4] Substance Abuse and Mental Health Services Administration (SAMHSA), "National Survey on Drug Use and Health,” DHHS, Rockville, 2004. http://oas.samhsa.gov/NSDUH/2k4nsduh/2k4tabs/toc

[5] ONDCP (Office of National Drug Control Policy), "Drug Abuse in America," Office of National Drug Control Policy, Washington DC, 2002. http://www.whitehousedrugpolicy.gov

[6] E. Puigdollers, A. Domingo-Salvany and M. T. Brugal "Characteristics of Heroin Addicts Entering Methadone Maintenance Treatment: Quality of Life and Gender," Substance Use \& Misuse, Vol. 39, No. 9, 2004, pp. 13531368. http://dx.doi.org/10.1081/JA-120039392

[7] P. Millson, L. Challacombe, P. J. Villeneuve, C. J. Strike, B. Fischer and T. Myers. "Determinants of Health-Related Quality of Life of Opiate Users at Entry to LowThreshold Methadone Programs," European Addiction Research, Vol. 12, 2006, pp. 74-82. http://dx.doi.org/10.1159/000090426

[8] P.E. Millson, L. Challacombe and P. J. Villeneuve, "SelfPerceived Health Among Canadian Opiate Users: A Comparison to the General Population and to Other Chronic Disease Populations." Canadian Journal of Public Health, Vol. 95, 2004, pp. 99-103.

[9] Y. Mizuno, D. Purcell, T. M. Borkowski, K. Knight and the SUDIS Team, "The Life Priorities of HIV-Seropositive Injection Drug Users: Findings from a Community-Based Sample,” AIDS and Behavior, Vol. 7, No. 4, 2003, pp. 395-403. http://dx.doi.org/10.1023/B:AIBE.0000004731.94734.77

[10] J. Bell and D. Zador, "A Risk-Benefit Analysis of Methadone Maintenance Treatment,” Drug Safety, Vol. 22, No. 3, 2000, pp. 179-190. http://dx.doi.org/10.2165/00002018-200022030-00002

[11] S. M. Giacomuzzi, M. Ertl, G. Kemmler, Y. Riemer and A. Vigl, "Sublingual Buprenorphine and Methadone Maintenance Treatment: A Three Year Follow-Up of Quality of Life Assessment," The Scientific World Journal, Vol. 5, 2005, pp. 452-468.

http://dx.doi.org/10.1100/tsw.2005.52

[12] V. Giedrius, Z. Padaiga and E. Bagdonas. "Cost-Utility Analysis of Methadone Maintenance Treatment: A Methodological Approach,” Substance Use \& Misuse, Vol. 41, No. 1, 2006, pp. 87-101.

http://dx.doi.org/10.1080/10826080500368751

[13] Office of National Drug Control Policy (ONDCP), "Methadone. Fact Sheet," Office of National Drug Control Policy, Washington DC, 2000. http://www.whitehousedrugpolicy.gov

[14] L. Gowing, M. Farrell, R. Bornemann and R. Ali. "Substitution Treatment of Injecting Opioid Users for Prevention of HIV Infection,” The Cochrane Database of Systematic Reviews, 2004, Article ID: CD004145. 
[15] R. E. Johnson and J. C. McCaugh, "Buprenorphine and Naloxone for Heroin Dependence,” Current Psychiatry Reports, Vol. 2, 2000, pp. 519-526. http://dx.doi.org/10.1007/s11920-000-0012-8

[16] National Institute on Drug Abuse (NIDA), "Principles of Drug Addiction Treatment: A Research Based Guide," US Department of Health and Human Services, Washington DC, NIH Publication No. 00.-4180, 2000.

[17] Substance Abuse and Mental Health Services Administration (SAMHSA), "Clinical Guidelines for the Use of Buprenorphine in the Treatment of Opioid Addiction,” A Treatment Improvement Protocol, TIP 40. 2004. http://www.kap.samhsa.gov/products/manuals/index.htm

[18] SAMHSA (Substance Abuse and Mental Health Services Administration), "Medication Assisted Treatment for Opioid Addiction in Opioid Treatment Programs," Treatment Improvement Protocol (TIP) 43. 2005; DHHS Publication No. 05-4048. Rockville Maryland. http://www.dpt.samhsa.gov/reports/index.htm

[19] T. F. Kresina, K. Hoffman and R. Lubran, “A Pilot Hepatitis Vaccination Program for Substance Abuse Treatment Settings," The 2005 CDC HCV Prevention Conference, Washington DC, 5-9 December 2005, p. 21. http://www.cdc.gov/hepatitis/Resources/MtgsConf/NatV HPrevConf2005/Agenda-NVHPC2005.pdf

[20] T. F. Kresina, C. Maxwell, M. W. Parrino and R. Lubran, “Testing and Counseling for Hepatitis B, Hepatitis C, and HIV Infections in Opioid Treatment Programs (OTP's). Summary Results from Two Surveys,” The 2005 CDC HCV Prevention Conference, Washington DC, 5-9 December 2005, p. 17.

http://www.cdc.gov/hepatitis/Resources/MtgsConf/NatV HPrevConf2005/Agenda-NVHPC2005.pdf

[21] M. A. Bachhuber and C. O. Cunningham, "Changes in Testing for Human Immunodeficiency Virus, Sexually Transmitted Infections, and Hepatitis C Virus in Opioid Treatment Programs," The Journal of the American Medical Association, Vol. 310, No. 24, 2013, pp. 2671-2672. http://dx.doi.org/10.1001/jama.2013.278456

[22] J.A. Frimpong, "Missed Opportunities for Hepatitis C Testing in Opioid Treatment Programs," American Journal of Public Health, Vol. 103, No. 6, 2013, pp. 10281030. http://dx.doi.org/10.2105/AJPH.2012.301129

[23] B. R. Edlin, T. F. Kresina and D. B. Raymond, "Care for Hepatitis C Disease and Barriers to Care among Injection Drug Users,” Clinical Infectious Diseases, Vol. 40, Suppl. 3, 2005, pp. S276-S285. http://dx.doi.org/10.1086/427441

[24] M. Backmund, K. Meyer and C. Henkel, "Risk Factors and Predictors of Human Immunodeficiency Virus Infection Among Injection Drug Users,” European Addiction Research, Vol. 11, No. 3, 2005, pp. 138-144. http://dx.doi.org/10.1159/000085549

[25] I. Kuo, S. G. Sherman, D. L. Thomas and S. A. Strathdee, "Hepatitis B Virus Infection and Vaccination Among Young Injection and Non-Injection Drug Users: Missed Opportunities to Prevent Infection,” Drug and Alcohol Dependence, Vol. 73, No. 1, 2004, pp. 69-78. http://dx.doi.org/10.1016/j.drugalcdep.2003.10.007

[26] J. E. Zweben, "Hepatitis C: Education and Counseling Is- sues," Journal of Addictive Diseases, Vol. 20, No. 1, 2001, pp. 33-42.

http://dx.doi.org/10.1300/J069v20n01_04

[27] D. A. Fiellin, R. A. Rosenheck and T. R. Kosten, "Coordination of Medical Care and Opioid Dependence Treatment in Primary Care: A Case Report," Substance Abuse, Vol. 24, No. 1, 2003, pp. 24:43-46.

[28] C. Bachireddy, C. S. Soule, J. M. Izenberg, S. Dvoryak, K. Dumchev and F. L. Altice, "Integration of Health Services Improves Multiple Healthcare Outcomes Among HIV-Infected People Who Inject Drugs in Ukraine,” Drug and Alcohol Dependence, Vol. 143, 2014, pp. 106-114. http://dx.doi.org/10.1016/j.drugalcdep.2013.09.020

[29] National Institutes of Health (NIH), Consensus Development Conference Statement, "Management of Hepatitis C: 2002,” Final Statement August 26, 2002.

http://consensus.nih.gov

[30] M. Schaefer, A. Heinz and M. Backmund. "Treatment of Chronic Hepatitis C in Patients with Drug Dependence: Time to Change the Rules?” Addiction, Vol. 99, No. 9, 2004, pp. 1167-1175. http://dx.doi.org/10.1111/j.1360-0443.2004.00821.x

[31] B. R. Edlin, K. H. Seal and J. Lorvick, “Is It Justifiable to Withhold Treatment for Hepatitis C From Illicit-Drug Users?” New England Journal of Medicine, Vol. 345, No. 3, 2001, pp. 211-214. http://dx.doi.org/10.1056/NEJM200107193450311

[32] G. J. Dore and D. L. Thomas, "Management and Treatment of Injection Drug Users with Hepatitis C Virus (HCV) Infection and HCV/Human Immunodeficiency Virus Coinfection,” Seminars in Liver Disease, Vol. 25, No. 1, 2005, pp. 18-32. http://dx.doi.org/10.1055/s-2005-864779

[33] R. C. Botero, "Should Patients with Chronic Hepatitis C Infection Be Transplanted?” Transplantation Proceedings, Vol. 36, No. 5, 2004, pp. 1449-1454. http://dx.doi.org/10.1016/j.transproceed.2004.06.003

[34] Centers for Disease Control and Prevention (CDC), "Recommendations for Prevention and Control of Hepatitis C Virus (HCV) Infection and HCV-Related Chronic Disease," Morbidity and Mortality Weekly Report, Vol. 47, No. RR-19, 1998, pp. 1-39.

[35] G. L. Davis and J. R. Rodrigue, "Treatment of Chronic Hepatitis C in Active Drug Users,” New England Journal of Medicine, Vol. 345, No. 3, 2001, pp. 215-217. http://dx.doi.org/10.1056/NEJM200107193450312

[36] J. J. McCarthy and N. Flynn, "Hepatitis C in Methadone Maintenance Patients: Prevalence and Public Policy Implications,” Journal of Addictive Diseases, Vol. 20, No. 1, 2001, pp. 19-31. http://dx.doi.org/10.1300/J069v20n01_03

[37] M. D. Stein, J. Maksad and J. Clarke, "Hepatitis C Disease among Injection Drug Users: Knowledge, Perceived Risk and Willingness to Receive Treatment," Drug and Alcohol Dependence, Vol. 61, No. 3, 2001, pp. 211-215. http://dx.doi.org/10.1016/S0376-8716(00)00144-7

[38] United States Department of Health and Human Services, "Combating the Silent Epidemic of Viral Hepatitis. Action Plan for the Prevention, Care and Treatment of Viral 
Hepatitis,” 2011.

http://www.hhs.gov/ash/initiatives/hepatitis/actionplan_vi ralhepatitis2011.pdf

[39] US Preventive Services Task Force, "Screening for Hepatitis C Virus Infection in Adults: Final Recommendation Statement,” AHRQ Publication No. 12-05174-EF-2, 2013. http://www.uspreventiveservicestaskforce.org/uspstf12/he pc/hepcfinalrs.htm.

[40] C. K. Aitken, M. Kerger and N. Crofts, "Peer-Delivered Hepatitis C Testing and Counseling: A Means of Improving the Health of Injection Drug Users," Drug and Alcohol Review, Vol. 21, No. 1, 2002, pp. 33-37. http://dx.doi.org/10.1080/09595230220119327

[41] A. H. Talal, R. B. Dimova, R. Seewald, R. H. Peterson, M. Zeremski and D. C. Perlman, "Assessment of Methadone Clinic Staff Attitudes toward Hepatitis C Evaluation and Treatment," Journal of Substance Abuse Treatment, Vol. 44, No. 1, 2013, pp. 115-119. http://dx.doi.org/10.1016/j.jsat.2012.01.010

[42] S. Mauss, F. Berger, J. Goelz, B. Jacob and G. Schmutz, "A Prospective Controlled Study of Interferon-Based Therapy of Chronic Hepatitis C in Patients on Methadone Maintenance,” Hepatology, Vol. 40, No. 1, 2004, pp. 120-124. http://dx.doi.org/10.1002/hep.20279

[43] M. Schaefer, F. Schmidt and C. Folwaczny, "Adherence and Mental Side Effects During Hepatitis C Treatment with Interferon Alpha and Ribavirin in Psychiatric Risk Groups,” Hepatology, Vol. 37, No. 2, 2003, pp. 443-451. http://dx.doi.org/10.1053/jhep.2003.50031

[44] D. H. Van Thiel, A. Anantharaju and S. Creech, "Response to Treatment of Hepatitis C in Individuals with a Recent History of Intravenous Drug Abuse,” American Journal of Gastroenterology, Vol. 98, No. 10, 2003, pp. 2281-2288. http://dx.doi.org/10.1016/S0002-9270(03)00708-1

[45] D. L. Sylvestre, A. H. Litwin, B. J. Clements and M. N. Gourevitch, "The Impact of Barriers to HCV Treatment in Recovering Heroin Users Maintained on Methadone," Journal of Substance Abuse Treatment, Vol. 29, No. 3, 2005, pp. 159-165. http://dx.doi.org/10.1016/j.jsat.2005.06.002

[46] A. H. Litwain, K. A. Harris, S. Nahvi, P. J. Zamor, I. J. Soloway and P. L. Tenore, "Successful Treatment of Chronic Hepatitis with Pegylated Interferon in Combination with Ribavirin in a Methadone Maintenance Treatment Program,” Journal of Substance Abuse Treatment, Vol. 37, No. 1, 2009, pp. 32-40. http://dx.doi.org/10.1016/j.jsat.2008.09.009

[47] L. E. Taylor, S. E. Bowman, S. Chapman, N. Zaller, M. D. Stein and P. A. Cioe, "Treatment for Hepatitis C Virus Genotype 1 Infection in HIV-Infected Individuals on Methadone Maintenance Therapy,” Drug and Alcohol Dependence, Vol. 116, No. 1-3, 2011, pp. 233-237.

http://dx.doi.org/10.1016/j.drugalcdep.2010.11.016

[48] A. Charlebois, L. Lee, E. Cooper, K. Mason and J. Powis, "Factors Associated with HCV Antiviral Treatment Uptake among Participants of a Community-Based HCV Programme for Marginalized Patients,” Journal of Viral Hepatitis, Vol. 19, No. 12, 2012, pp. 836-842. http://dx.doi.org/10.1111/j.1365-2893.2012.01648.x
[49] A. Saxon, W. Ling, M. Hillhouse, C. Thomas, A. Hasson and A. Ang, "Buprenorphine/Naloxone and Methadone Effects on Laboratory Indices of Liver Health: A Randomized Trial,” Drug and Alcohol Dependence, Vol. 128, No. 1-2, 2013, pp. 71-76. http://dx.doi.org/10.1016/j.drugalcdep.2012.08.002

[50] D. B. Strader, T. Wright, D. L. Thomas and L. Seeff, "Diagnosis, Management and Treatment of Hepatitis C. AASLD Practice Guideline,” Hepatology, Vol. 39, No. 4, 2004, pp. 1147-1171. http://dx.doi.org/10.1002/hep.20119

[51] American Association for the Study of Liver Disease (AASLD), "Diagnosis, Management and Treatment of Hepatitis C, AASLD Practice Guideline,” Hepatology, Vol. 39, No. 4, 2004, pp. 1147-1171. http://dx.doi.org/10.1002/hep.20119

[52] M. J. Alter, D. Kruszon-Moran and O. V. Nainan, “The Prevalence of Hepatitis C Infection in the United States, 1988 through 1994,” New England Journal of Medicine, Vol. 341, 1999, pp. 556-562. http://dx.doi.org/10.1056/NEJM199908193410802

[53] C. Boesecke, H. Wedemeyer and J. K. Rockstroh, "Diagnosis and Treatment of Acute Hepatitis C Virus Infection," Infectious Disease Clinics of North America, Vol. 26, No. 4, 2012, pp. 995-1010. http://dx.doi.org/10.1016/j.idc.2012.08.011

[54] J. Grebely, G. V. Matthews and G. J. Dore, “Treatment of Acute HCV Infection,” Nature Reviews Gastroenterology \& Hepatology, Vol. 8, 2011, pp. 265-274.

[55] G. Nunnari, A. Montineri, V. Portelli, F. Savalli, F. Fatuzzo and B. Cacopardo, "The Use of Peginterferon in Monotherapy or in Combination with Ribavirin for the Treatment of Acute Hepatitis C," European Review for Medical and Pharmacological Sciences, Vol. 16, No. 8, 2012, pp. 10131016.

[56] B. Hajarizadeh, J. Grebely and G. J. Dore, "Case Definitions for Acute Hepatitis C Virus Infection: A Systematic Review,” Journal of Hepatology, Vol. 57, No. 6, 2012, pp. 1349-1360. http://dx.doi.org/10.1016/j.jhep.2012.07.007

[57] E. Jaeckel, M. Cornberg, H. Wedemeyer, et al., "Treatment of Acute Hepatitis with Interferon Alfa-2b,” New England Journal of Medicine, Vol. 345, No. 20, 2001, pp. 1452-1457. http://dx.doi.org/10.1056/NEJMoa011232

[58] H. Nomura, S. Sou, H. Tanimoto, T. Nagahama, Y. Kimura, J. Hayashi, H. Ishibashi and S. Kashiwagi, "Short-Term Interferon-Alpha Therapy for Acute Hepatitis C: A Randomized Controlled Trial,” Hepatology, Vol. 39, No. 5, 2004, pp. 1213-1219. http://dx.doi.org/10.1002/hep.20196

[59] T. Santantonio, “Treatment of Acute Hepatitis C," Current Pharmaceutical Design, Vol. 10, No. 17, 2004, pp. 2077-2080. http://dx.doi.org/10.2174/1381612043384222

[60] S. M. Kamal, K. N. Moustafa, J. Chen, J. Fehr, A. A. Moneim, K. E. Khalifa, L. A. El Gohary, A. H. Ramy, M. A. Madwar, J. Rasenack and N. H. Afdha, "Duration of Peginterferon Therapy in Acute Hepatitis C: A Randomized Trial,” Hepatology, Vol. 43, No. 5, 2006, pp. 923-931. http://dx.doi.org/10.1002/hep.21197

[61] J. Weigand, P. Buggisch, W. Boecher, S. Zeuzem, C. M. Gelbmann, T. Bergs, W. Kauffmann, B. Kallinowski, M. 
Cornberg, E. Jaeckel, H. Wedemeyer and M. Manns, "Early Monotherapy with Pegylated Interferon Alpha-2b for Acute Hepatitis C Infection: The HEP-NET Acute-HCV-II Study,” Hepatology, Vol. 43, No. 2, 2006, pp. 250-256. http://dx.doi.org/10.1002/hep.21043

[62] D. L. Thomas, "Advances in the Treatment of Hepatitis C Virus Infection,” Topics in Antiviral Medicine, Vol. 20, No. 1, 2012, pp. 5-10.

[63] S. Sockalingam, A. Tseng, P. Giguere and D. Wong, "Psychiatric Treatment Considerations with Direct Acting Antivirals in Hepatitis C,” BMC Gastroenterolohy, Vol. 13, 2013, pp. 86-96. http://dx.doi.org/10.1186/1471-230X-13-86

[64] “FDA Approves Sovaldi for Chronic Hepatitis C," FDA New Release, US Food and Drug Administration, 6 December 2013.

[65] P. J. Pockros, "Nucleoside/Nucleotide Analogue Polymerase Inhibitors in Development," Clinics in Liver Disease, Vol. 17, No. 1, 2013, pp. 105-110. http://dx.doi.org/10.1016/j.cld.2012.09.007

[66] N. K. Martin, et al., "HCV Treatment for Prevention among People Who Inject Drugs: Modeling Treatment Scale-up in an Age of Direct Acting Antivirals," Hepatology, Vol. 58, No. 5, 2013, pp. 1598-1609.

[67] J. Stephenson, "Former Addicts Face Barriers to Treatment for HCV," The Journal of the American Medical Association, Vol. 285, No. 8, 2001, pp. 1003-1005. http://dx.doi.org/10.1001/jama.285.8.1003

[68] M. Schafer, "Psychiatric Patients, Methadone Patients, and Earlier Drug Users Can Be Treated for HCV When Given Adequate Support Services," Presentation at Digestive Disease Week, Atlanta, 20-23 May 2001.

[69] H. Hagan, H. Haynes, R. A. Willson, T. R. Jackson and E. R. Alexander, "Feasibility of Alpha-Interferon Administration to Opiate Addicts in a Methadone Treatment Setting," Hepatology, Vol. 30, No. 4, 1999, pp. 624-629.

[70] D. L. Sylvestre, J. M. Loftis, P. Hauser, S. Genser, H. Cesari, N. Borek, T. F. Kresina, L. Seeff and H. Francis, "Co-Occurring Hepatitis C, Substance Use and Psychiatric Illness: Treatment Issues and Developing Integrated Models of Care," Journal of Urban Health, Vol. 81, No.
4, 2004, pp. 719-734.

http://dx.doi.org/10.1093/jurban/jth153

[71] A. H. Litwin, K. M. Berg, X. Li, J. Hidalgo and J. H. Arnsten, "Rationale and Design of a Randomized Controlled Trial of Directly Observed Hepatitis C Treatment Delivered in Methadone Clinics,” BMC Infectious Diseases, Vol. 11, 2011, pp. 315-334. http://dx.doi.org/10.1186/1471-2334-11-315

[72] R. D. Bruce, J. Eiserman, A. Acosta, C. Gote, J. K. Lim and F. L. Altice, "Developing a Modified Directly Observed Therapy Intervention for Hepatitis C Treatment in a Methadone Maintenance Program: Implications for Program Replication," American Journal of Drug and Alcohol Abuse, Vol. 38, No. 3, 2012, pp. 206-212. http://dx.doi.org/10.3109/00952990.2011.643975

[73] M. R. Stein, I. J. Soloway, K. S. Jefferson, R. J. Roose, J. H. Arnsten and A. H. Litwin, "Concurrent Group Treatment for Hepatitis C: Implementation and Outcomes in a Methadone Maintenance Treatment Program," Journal of Substance Abuse Treatment, Vol. 43, No. 4, 2012, pp. 424432. http://dx.doi.org/10.1016/j.jsat.2012.08.007

[74] C. L. Masson, K. L. Delucchi, C. McKnight, J. Hettema, M. Khalilli, A. Min, et al., "A Randomized Trial of a Hepatitis Care Coordination Model in Methadone Maintenance Treatment,” American Journal of Public Health, Vol. 103, No. 10, 2013, pp. e81-e88. http://dx.doi.org/10.2105/AJPH.2013.301458

[75] N. Durier, C. Nguyen and L. J. White, “Treatment of Hepatitis C as Prevention: A Modeling Case Study in Vietnam,” PloS ONE, Vol. 7, No. 4, 2012, Article ID: e34548. http://dx.doi.org/10.1371/journal.pone.0034548

[76] S. M. Alavain, A. Mirahmadizadeh, M. Javanbakht, A. Keshtkaran, A. Heidari, A. Mashayekhi, S. Salimi and M. Hadian, "Effectiveness of Methadone Maintenance Treatment in Prevention of Hepatitis C Virus Transmission among Injection Drug Users,” Hepatitis Monthly, Vol. 13, No. 8, 2013, Article ID: e12411.

[77] Medecins Sans Frontiers, "Diagnosis and Treatment of Hepatitis C: A Technical Landscape. Opportunities to Revolutionise Care in Developing Countries,” April 2013. http://www.msfaccess.org/our-work/hiv-aids/article/2024 